\title{
Stem-root flow effect on soil-atmosphere interactions and uncertainty assessments
}

\author{
Tzu-Hsien Kuo ${ }^{1}$, Jen-Ping Chen ${ }^{1}$, and Yongkang Xue ${ }^{2}$ \\ ${ }^{1}$ Department of Atmospheric Sciences, National Taiwan University, Taipei, Taiwan, Republic of China \\ ${ }^{2}$ Department of Atmospheric and Oceanic Sciences, and Department of Geography, University of California, Los Angeles, \\ California, USA \\ Correspondence to: Jen-Ping Chen (jpchen@as.ntu.edu.tw)
}

Received: 1 October 2015 - Published in Hydrol. Earth Syst. Sci. Discuss.: 11 November 2015

Revised: 26 February 2016 - Accepted: 5 April 2016 - Published: 20 April 2016

\begin{abstract}
Rainfall that reaches the soil surface can rapidly move into deeper layers in the form of bulk flow through the stem-root flow mechanism. This study developed the stemroot flow parameterization scheme and coupled this scheme with the Simplified Simple Biosphere model (SSiB) to analyze its effects on land-atmospheric interactions. The SSiB model was tested in a single-column mode using the Lien Hua Chih (LHC) measurements conducted in Taiwan and HAPEX-Mobilhy (HAPEX) measurements in France. The results show that stem-root flow generally caused a decrease in soil moisture in the top soil layer and moistened the deeper soil layers. Such soil moisture redistribution results in substantial changes in heat flux exchange between land and atmosphere. In the humid environment at LHC, the stem-root flow effect on transpiration was minimal, and the main influence on energy flux was through reduced soil evaporation that led to higher soil temperature and greater sensible heat flux. In the Mediterranean environment of HAPEX, the stem-root flow substantially affected plant transpiration and soil evaporation, as well as associated changes in canopy and soil temperatures. However, the effect on transpiration could be either positive or negative depending on the relative changes in the soil moisture of the top soil vs. deeper soil layers due to stem-root flow and soil moisture diffusion processes.
\end{abstract}

\section{Introduction}

The water stored in the land system is a key factor controlling many physical processes and feedback between the land and atmosphere. Soil moisture is a source of water for the atmosphere through processes that lead to evapotranspiration, including bare soil evaporation, plant transpiration and evaporation from other surfaces such as leaves, snow, etc. The rainfall redistribution process in forest systems affects soil moisture amount and its distribution (McGuffie et al., 1995; Chase et al., 1996, 2000; Zhao et al., 2001). Rainwater entering the forest is redistributed via several pathways before reaching the forest floor, e.g., some is intercepted by the canopy and some reaches the soil as throughfall. A significant amount of rainwater intercepted by the canopy can flow down along tree stems and reach the forest floor in a process termed stemflow. The efficiency of stemflow varies with plant species, seasons, meteorological conditions, rainfall intensity and canopy structure (Levia and Frost, 2003; Levia and Germer, 2015). Johnson and Lehmann (2006) summarized various field measurements and showed that the fraction of precipitation that becomes stemflow ranges from 0.07 to $22 \%$.

In contrast to the throughfall that infiltrates slowly through the top soil, stemflow can continue via the root system (hereafter called the stem-root flow) and quickly reach deep soil layers and the water table (Liang et al., 2007, 2009). It has long been recognized that the stem-root flow can help to store water in deeper soil layers and thus create favorable conditions for plant growth under arid conditions (Návar, 1993; Li et al., 2009). Soil moisture redistribution 
by stem-root flow not only affects vegetation growth but also land evapotranspiration and runoff (Neave and Abrahams, 2002). Furthermore, the enhanced water penetration can significantly alter groundwater recharge. Taniguchi et al. (1996) showed that in a pine forest, the stem-root flow contributed approximately 10-20\% of annual groundwater recharge even with a stemflow-to-precipitation ratio of only $1 \%$.

Stem-root flow effects have not been considered in most land surface schemes of climate models. Tanaka et al. (1996) developed a model to evaluate the effect of stem-root flow on groundwater. This model is yet to be implemented in current land surface models. Li et al. (2012) pointed out that stemflow hydrology and preferential flow along roots are intimately linked, but direct integration of these processes into land models, to our knowledge, has not been reported.

In this paper, we parameterized the stem-root flow processes in a land surface model named the Simplified Simple Biosphere Model (SSiB; Xue et al., 1991), and analyzed how stem-root flow affects soil moisture and whether this effect is significant enough to influence atmospheric processes. Soil moisture data from two sites, located at Lien Hua Chih, Taiwan (LHC), and Bordeaux/Toulouse, France (from the HAPEX-Mobilhy experiment, hereafter called HAPEX), were collected for model evaluation. The two sites represent different climate regimes and terrestrial ecosystems, and stem-root flow modifies their surface energy and water processes in somewhat dissimilar ways.

\section{Methodology}

\subsection{The stem-root flow model}

In the original SSiB land surface model (Xue et al., 1996), vertical soil moisture movement is described by the diffusion equations:

$$
\begin{aligned}
\frac{\partial \theta_{1}}{\partial t} & =\frac{1}{D_{1}}\left[P+Q_{12}-E_{\mathrm{SE}}-b_{1} E_{\mathrm{TR}, 1}\right] \\
\frac{\partial \theta_{2}}{\partial t} & =\frac{1}{D_{2}}\left[-Q_{12}+Q_{23}-b_{2} E_{\mathrm{TR}, 2}\right] \\
\frac{\partial \theta_{3}}{\partial t} & =\frac{1}{D_{3}}\left[-Q_{23}+Q_{3}-b_{3} E_{\mathrm{TR}, 3}\right]
\end{aligned}
$$

where the subscripts 1,2 and 3 are indices of the top, middle and bottom soil layers, respectively; $\theta$ is the soil moisture content, expressed as a fraction of the saturated value; $D$ is soil thickness; $P$ is effective precipitation flux on the soil surface, composed of the direct throughfall and the throughfall from leave-intercepted rainfall (cf. Fig. 1); $Q_{i j}=-k[\partial \Psi / \partial z+1]$ is the flux of water between the $i$ th and $j$ th layers, and is defined to be positive in an upward direction; $\Psi$ (in m) is the soil water potential; $E_{\mathrm{SE}}$ is the evaporation rate of bare soil; $i$ is the soil layer index; $E_{\mathrm{TR}, i}$ is the transpiration rate in soil layer; $b_{i}$ is the proportionality factor that accounts for root distribution; $Q_{3}$ is the water flux entering the water table. A similar approach has been used by many land surface models. Note that the middle soil layer can be divided into more sublayers with a similar formula to that used for the middle layer. In these equations, the transfer velocity $Q_{i j}$ considers only the soil diffusion flow. This study develops the parameterizations that include the stemroot flow mechanism which provides a bypass for water to channel through the soil on root surfaces (Fig. 1). The stemflow reaching the top soil layer, $q_{0}$, is often represented as a fraction of the total precipitation (or, more precisely, the leaf drainage) such that direct rainfall entering the soil becomes

$P^{\prime} \equiv P-q_{0}$

By relating the stemflow to leaf drainage, there is an implicit threshold for stemflow initiation that corresponds to the threshold of leaf drainage.

After entering the soil, the root flow is divided into a downward transfer flux $q_{z}$ (within the root system) and a lateral transfer flux $q_{x}$ (from the root surface to the soil). These two fluxes can be parameterized as follows:

$q_{z, i}=\alpha_{z} A_{i} h_{i} V_{\mathrm{s}}$
$q_{x, i}=\left\{\begin{array}{ll}\alpha_{x} R_{i} A_{i} K\left(\Psi_{i}\right)\left(\frac{\Psi_{i}-\Psi_{\mathrm{s}}}{D_{\text {eff }}}\right) & \text { if } h_{i}>0 \\ 0, & \text { if } h_{i}=0\end{array}\right.$,

where $\alpha_{z}$ and $\alpha_{x}$ are proportionality coefficients; $A_{i}$ (in $\mathrm{m}^{2} \mathrm{~m}^{-3}$ ) is the total root surface area density that varies with vegetation types (Böhm, 1979; Zhang et al., 2005; Li et al., 2013); $h_{i}$ (in $\mathrm{m}$ ) is the thickness of water on the root surface; $V_{\mathrm{S}}\left(\right.$ in $\mathrm{m} \mathrm{s}^{-1}$ ) is the terminal velocity of root flow; $R_{i}$ (in $\mathrm{m}$ ) is the root length; $K$ (in $\mathrm{m} \mathrm{s}^{-1}$ ) is the hydraulic conductivity of the soil; $\Psi_{\mathrm{s}}$ (in $\mathrm{m}$ ) is the soil water potential at saturation; $\Psi_{i}$ (in m) is the soil water potential; $D_{\text {eff }}$ (in m) is the effective thickness of the water-soil interface. Derivation of $D_{\text {eff }}$ is described in the Appendix. Due to a lack of observational data, we used a vertically uniform root distribution. However, different root depths were used based on the measurements $(100 \mathrm{~cm}$ for LHC and $140 \mathrm{~cm}$ for HAPEX). Note that $q_{0}=q_{x, 1}+q_{z, 1}$ according to the mass conservation principle. From Eqs. (1), (2) and (3), we have

$$
\begin{aligned}
\frac{\partial \theta_{1}}{\partial t} & =\frac{1}{D_{1}}\left[P^{\prime}+Q_{12}-E_{\mathrm{SE}}-b_{1} E_{\mathrm{TR}, 1}+q_{x, 1}\right] \\
\frac{\partial \theta_{2}}{\partial t} & =\frac{1}{D_{2}}\left[-Q_{12}+Q_{23}-b_{2} E_{\mathrm{TR}, 2}+q_{x, 2}\right] \\
\frac{\partial \theta_{3}}{\partial t} & =\frac{1}{D_{3}}\left[-Q_{23}+Q_{3}-b_{3} E_{\mathrm{TR}, 3}+q_{x, 3}\right] .
\end{aligned}
$$

The changes in root surface water thickness $h_{i}$ obey the mass conservation principle and thus are controlled by the vertical and horizontal fluxes of root flow. Its tendency can be de- 


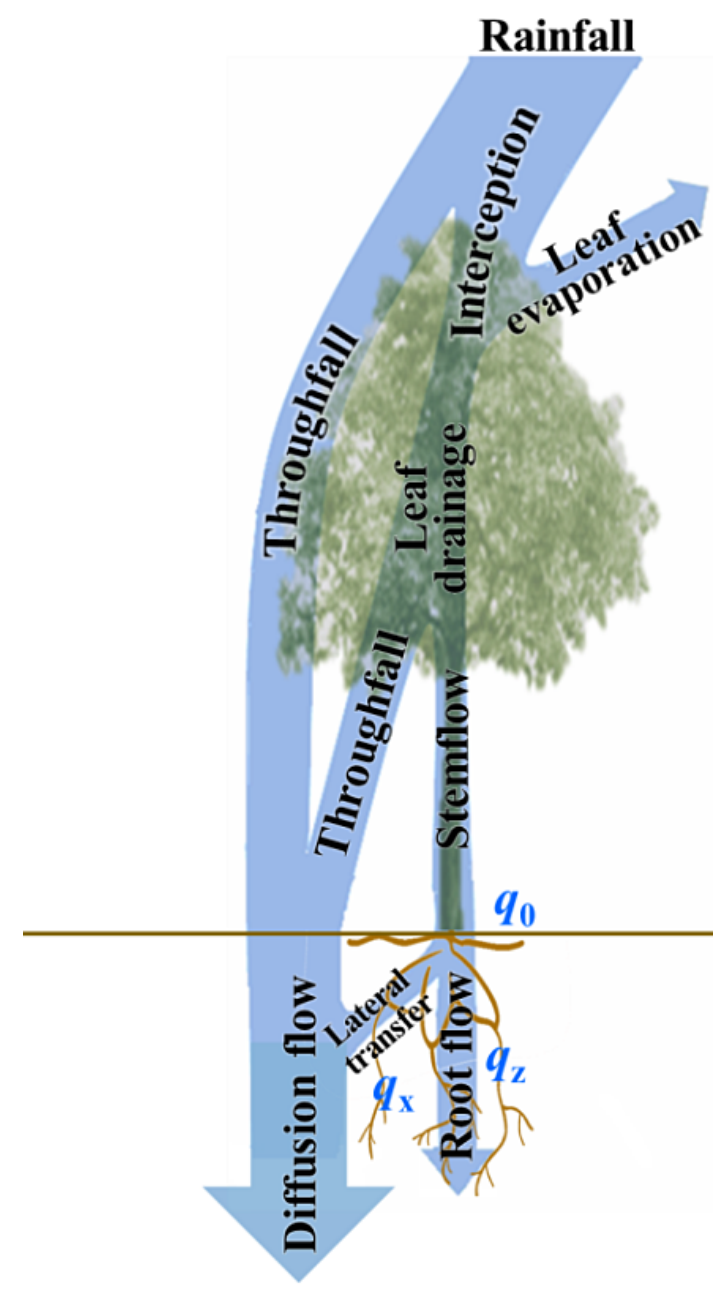

Figure 1. Stem-root flow conceptual diagram. Leaf drainage in the model can be separated into throughfall and stemflow. Following the stemflow path, rainwater can continue via the root system to reach deep soil layers and the water table. The stemflow that reaches the top soil layer, $q_{0}$, is divided into a downward transfer flux (i.e., the root flow) $q_{z}$ and a lateral transfer flux $q_{x}$ (from the root surface to the soil), and the two transfer fluxes regulate the root-flow thickness.

scribed as

$\frac{\mathrm{d} h_{i}}{\mathrm{~d} t}=\left\{\begin{array}{ll}\frac{\left(q_{z, i-1}-q_{z, i}-q_{x, i}\right)}{A_{i} R_{i}} & \text { if } h_{i}>0 \\ 0, & \text { if } h_{i}=0\end{array}\right.$.

Equations (5) and (6) represent the water budgets in the soil and root-flow systems, respectively, and they are linked through the term $q_{x}$ in Eq. (4).

Stemflow input into the first soil layer $\left(q_{0}\right)$ is represented as a fraction of the leaf drainage (LD), which is the portion of precipitation that is intercepted by the canopy minus leaf evaporation and can be calculated in SSiB. LD is similar to canopy drip in some other models, and is represented mainly as a function of the leaf area index (LAI). The stemflow to leaf drainage ratio (SLR; i.e., $q_{0} / \mathrm{LD}$ ) depends mainly on plant type, as well as meteorological conditions such as wind speed (Levia and Frost, 2003; Johnson and Lehmann, 2006; André et al., 2008; Siegert and Levia, 2014). Unfortunately, there is still insufficient information to determine SLR. We conducted a series of sensitivity tests with systematically varying SLR to assess the uncertainty.

The stem-root flow parameterization was tested using the offline $\mathrm{SSiB}$, which is a simplified version of the landbiosphere model developed by Sellers et al. (1986). The model recognizes 12 different vegetation types according to Dorman and Sellers (1989), and is set up with three soil layers and one canopy layer. The SSiB model has eight prognostic variables: soil wetness for three layers; temperature at the canopy, ground surface and deep soil layers; snow depth at ground level; and water intercepted by the canopy. An additional variable $-h_{i}$ - was added for each soil layer to account for the stem-root flow mechanism. An implicit backward scheme was used to calculate the temperature tendency in the coupling of the lowest atmospheric model layer with $\mathrm{SSiB}$, such that energy conservation between the land surface and the atmosphere was satisfied. Soil temperature was calculated using the force-restore method, and water movement in the soil was described by the diffusion equation as shown in Eq. (5).

Following typical offline simulation procedures for a single-column land surface model, in situ atmospheric data were applied to drive the $\mathrm{SSiB}$ model in $30 \mathrm{~min}$ time resolution. These specified variables include pressure, temperature, humidity, wind speed, net radiation and rainfall. Soil conditions were initialized with each site's measurement data. The spin-up time for coupled land surface model typically ranges from a couple of months to over a year, but can be shorter when running in offline (single-column) mode and with good initial soil conditions (de Goncalves et al., 2006; Yang et al., 2011; Lim et al., 2012; Angevine et al., 2014). Our simulations applied measurement data for model initialization, and the results show that the soil conditions reached physical balance within a few weeks. Therefore, for the last 10 months, results of our simulations are reliable.

\subsection{Experimental design and site information}

Two sites with different climate and vegetation conditions were selected to test the stem-root flow parameterizations in the SSiB model. The first is a site with warm to temperate mountain rainforest conditions in Lien Hua Chi (LHC; $23^{\circ} 55^{\prime} \mathrm{N}, 120^{\circ} 53^{\prime} \mathrm{E}$ ), Taiwan. LHC is located in the Central Mountain Range of Taiwan, with a hilly terrain and a mean altitude of $770 \mathrm{~m}$ above sea level (a.s.l.) in the surroundings. The average annual rainfall at LHC is $2317 \mathrm{~mm}$, with rain falling predominantly in late summer and early autumn (Fig. 2). With ample rainfall, LHC is covered with dense forest with an average canopy height of approximately $17 \mathrm{~m}$. The vegetation cover is comprised of mixed evergreens and 


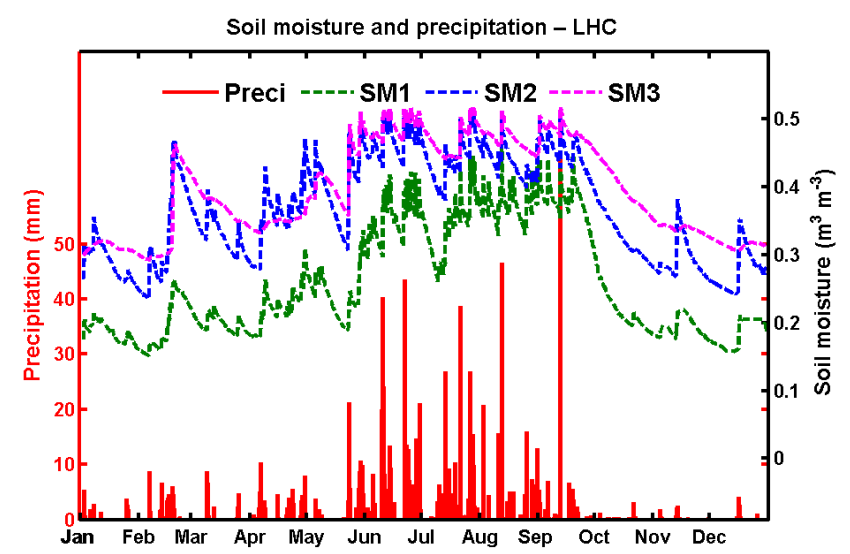

Figure 2. The hourly soil moisture (curves, right axis) and precipitation (red bars, left axis) observed at LHC during 2010. SM1, SM2 and SM3 represent soil moisture at $10 \mathrm{~cm}$ (green dashed curve), $40 \mathrm{~cm}$ (blue dashed curve; average of 30 and $50 \mathrm{~cm}$ observations) and $90 \mathrm{~cm}$ (magenta dashed curve), respectively.

hardwood species, including Cryptocarya chinensis, Engelhardtia roxburghiana, Tutcheria shinkoensis and Helicia formosana. The soil has a loamy texture with an average bulk density of $1.29 \mathrm{~g} \mathrm{~cm}^{-3}$ and a porosity of 0.53 over the top $1.0 \mathrm{~m}$ (Chen, 2012). Soil moisture measurements were collected at depths of 10,30,50,70 and $90 \mathrm{~cm}$.

The second site is the HAPEX-Mobilhy data collected at the Caumont site (SAMER station No. 3; $43^{\circ} 41^{\prime} \mathrm{N}, 0^{\circ} 6^{\prime} \mathrm{W}$ ) with an elevation of $113 \mathrm{~m}$ a.s.l. and relatively flat terrain. This site has a Mediterranean climate, with an annual rainfall of $856 \mathrm{~mm}$, most of which occurs in spring and winter (Fig. 3). In contrast to the LHC site with dense forest, the HAPEX site is covered mostly with short and sparse soya crops, and the surface albedo stays nearly constant at 0.20 throughout the year (Goutorbe et al., 1989). The soil type is mainly silt, mixed with sand and clay (see Table 1). Soil moisture content was measured every $10 \mathrm{~cm}$ from the surface to a depth of $1.6 \mathrm{~m}$ using neutron sounding probes on a weekly basis (Goutorbe, 1991; Goutorbe and Tarrieu, 1991). Note that the HAPEX data have higher vertical resolution in the soil column but lower temporal resolution compared with the LHC data. To simplify comparisons, the soil moisture data were converted into three vertical layers. For the HAPEX data, the top (SM1), middle (SM2) and bottom (SM3) layers correspond to the 0-20, 20-50 and 50-150 cm depths, respectively. For LHC, SM1 corresponds to a depth of $10 \mathrm{~cm}, \mathrm{SM} 2$ is the average of the 30 and $50 \mathrm{~cm}$ soil layers and $\mathrm{SM} 3$ corresponds to a depth of $90 \mathrm{~cm}$.

Figures 2 and 3 show the seasonal variations of precipitation and soil moisture at different depths. It is generally expected that soil moisture response to rainfall should be faster in the upper than in the lower layers. However, the LHC measurements (Fig. 2) showed that the soil moisture fluctuation was stronger in the middle layer than in the upper layer dur-

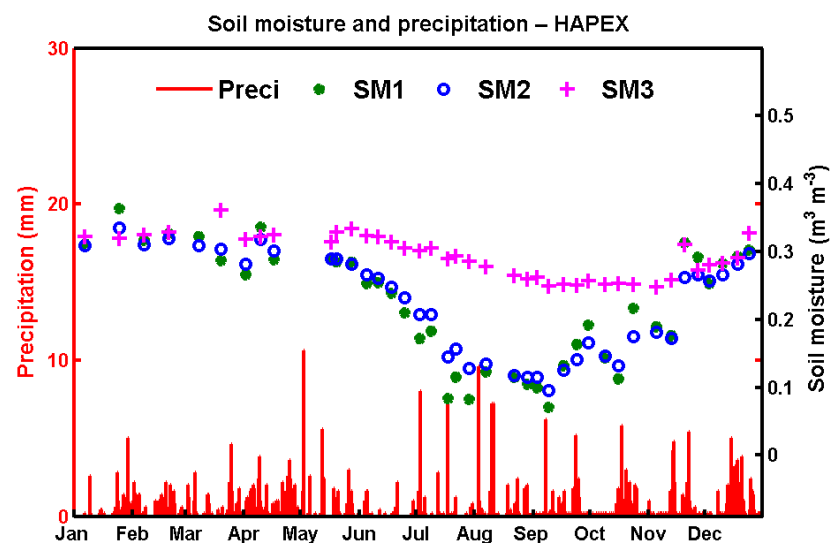

Figure 3. The weekly soil moisture (symbols, right axis) and hourly precipitation (red bars, left axis) observed at HAPEX during 1986. SM1, SM2 and SM3 represent the mean soil moisture in the 0$20 \mathrm{~cm}$ (green dot), 20-50 cm (blue circle) and 50-160 cm (magenta cross) layers, respectively.

ing the dry season when the soil moisture was not saturated. Fluctuations were not obvious in rainy seasons when SM2 and SM3 are almost saturated. This phenomenon is likely an indication of the preferential flow due to the root-flow mechanism. This phenomena, however, was not observed in the HAPEX data (Fig. 3), which may be due to the coarse temporal resolution (weekly) of the data or a weaker root-flow effect from the soya crop, and the latter will be discussed later. Figure 4 shows the correlation between hourly changes in precipitation and soil moisture at LHC in 2010. The correlations are higher at deeper layers and during stronger rainfall intensities. Such a relationship is a good indication of the stem-root flow mechanism.

To test the response of soil moisture to precipitation in these two sites using the modified SSiB model, a set of parameters have to be selected. These include the soil and terrain properties listed in Table 1, as well as the monthly LAI coefficients in Table 2. In addition, some parameters in Eqs. (3-6) have to be decided. Two required but little-known parameters are the root-flow velocity $V_{\mathrm{s}}$ and the SLR. The root-flow velocity $V_{\mathrm{s}}$ is related to root structure and soil texture, but such information is very limited. Studies have indicated that water flow in the root channel is approximately 100 times higher than the soil diffusion flow (Beven and Germann, 1982; Liu et al., 1994; Jarvis and Dubus, 2006; Köhne et al., 2009; Gerke, 2014). The maximum soil diffusion flow can be represented by the saturated hydraulic conductivity, which was measured as $4 \times 10^{-6} \mathrm{~m} \mathrm{~s}^{-1}$ at HAPEX and $1 \times 10^{-6} \mathrm{~m} \mathrm{~s}^{-1}$ at LHC. Therefore, we set the root-flow velocity $V_{\mathrm{s}}$ as $10^{-4} \mathrm{~m} \mathrm{~s}^{-1}$ in the simulation, and will discuss the associated uncertainty later.

The SLR value depends on a number of parameters as discussed in the previous section. This study evaluated SLRintroduced uncertainty by conducting sensitivity tests with 
Table 1. Basic parameters used for describing the LHC and HAPEX sites. LHC data were obtained from Wu (2011); HAPEX data were obtained from Goutorbe et al. (1989).

\begin{tabular}{lll}
\hline Location & LHC & HAPEX \\
\hline Annual rainfall & $2317 \mathrm{~mm}$ & $856 \mathrm{~mm}$ \\
Mean temperature & $19.7^{\circ} \mathrm{C}$ & $8.6^{\circ} \mathrm{C}$ \\
Altitude & $770 \mathrm{~m}$ & $113 \mathrm{~m}$ \\
Vegetation cover & Rainforest of mixed evergreens and hardwoods & Soya crop \\
Soil type & Loam & $17 \%$ clay content, $46 \%$ silt, $37 \%$ sand \\
Soil moisture measurement depth & $10,30,50,70,90 \mathrm{~cm}$ & Every 10 down to $160 \mathrm{~cm}$ \\
Soil wetness exponent & 2.5 & 5.66 \\
Soil tension at saturation & $-0.1 \mathrm{~m}$ & $-0.30 \mathrm{~m}$ \\
Hydraulic conductivity at saturation & $1 \times 10^{-6} \mathrm{~m} \mathrm{~s}^{-1}$ & $4 \times 10^{-6} \mathrm{~m} \mathrm{~s}^{-1}$ \\
Soil porosity & 0.530 & 0.446 \\
Slope & 0.55 & 0.05 \\
\hline
\end{tabular}

Table 2. Monthly leaf area index values (in $\mathrm{m}^{2} \mathrm{~m}^{-2}$ ) for LHC in 2010 and HAPEX in 1986. LHC data were obtained from Wu (2011); HAPEX data were obtained from Goutorbe et al. (1989).

\begin{tabular}{lllllllllllll}
\hline Month & 1 & 2 & 3 & 4 & 5 & 6 & 7 & 8 & 9 & 10 & 11 & 12 \\
\hline LHC & 3.34 & 3.08 & 3.06 & 3.04 & 4.35 & 4.77 & 4.84 & 4.91 & 4.66 & 4.4 & 4.2 & 4.25 \\
HAPEX & 0 & 0 & 0 & 0 & 1 & 3 & 3 & 3 & 3 & 0 & 0 & 0 \\
\hline
\end{tabular}

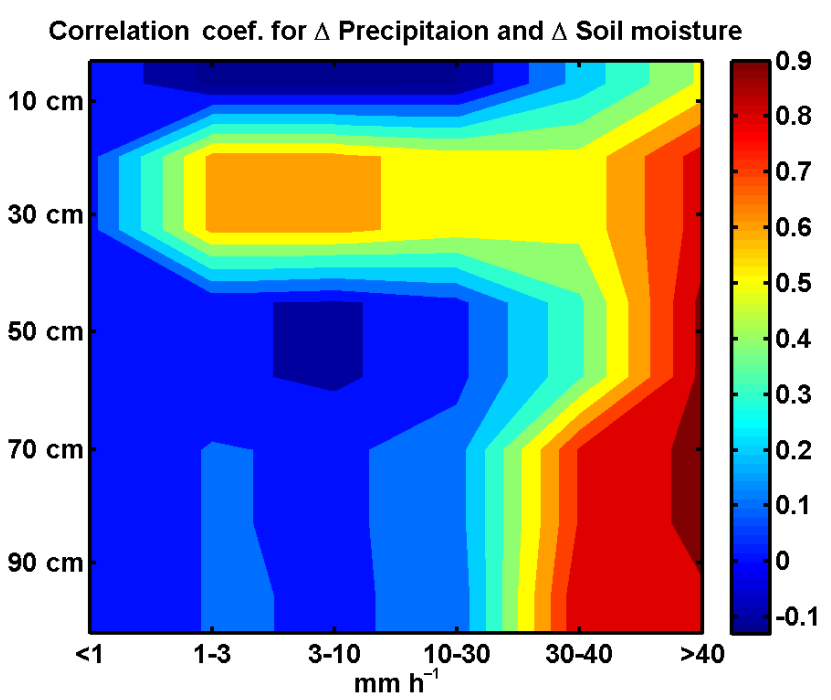

Figure 4. Correlation between hourly changes in precipitation and soil moisture at the Lien Hua Chih station in 2010. The ordinate is the soil depth and the abscissa is the rainfall intensity. Color shading indicates the correlation coefficient, with values shown in the color bar to the right.

systematically varying SLR from 0 to $100 \%$, and identified optimal value that yielded the best soil moisture profiles compared with the observations. The optimal SLR value for the HAPEX experiment was approximately $50 \%$, compared with $90 \%$ for the LHC case. These values reflect the large contrast in leaf coverage and plant type between the two sites.
In these experiments, we set $A_{i}$ to $0.5 \mathrm{~m}^{2} \mathrm{~m}^{-3}$ based on the study by Li et al. (2013), and the proportionality coefficients, $\alpha_{z}$ and $\alpha_{x}$, are set to 1 . The uncertainty discussion for $V_{\mathrm{s}}$ and SLR should include the uncertainty caused by these parameters. When more observational data are available, we could revisit these issues further. All simulations used an integration time step of $30 \mathrm{~min}$.

\section{Effect of stem-root flow on soil moisture}

The modified SSiB model was used to simulate the intraannual variations in soil conditions for the 2010 LHC case and the 1986 HAPEX case. For the LHC case, the simulation captured the soil moisture increase associated with precipitation events followed by rapid drying well (Fig. 5). Changes in SM1, SM2 and SM3 all reached the $95 \%$ confidence level in all seasons. In many instances, the simulated soil moisture fluctuation was stronger in the middle layer than in the top or bottom layers, as found in the observations. The shading shows the range of values enclosed by the two extremes of SLR (i.e., 0 and $100 \%$ ). Results with other SLR ratios (not shown) generally lie within these limits but may occasionally fall out of bounds, indicating some nonlinearities. When SLR is zero, which has no stem flow effect and is referred to as the control run in this paper, the soil moisture of the middle layer is very low and fluctuates less in response to rainfall events (Fig. 5). The simulation generally underestimated the soil moisture in the bottom layer even with the root-flow mechanism. In the top layer, the model overesti- 

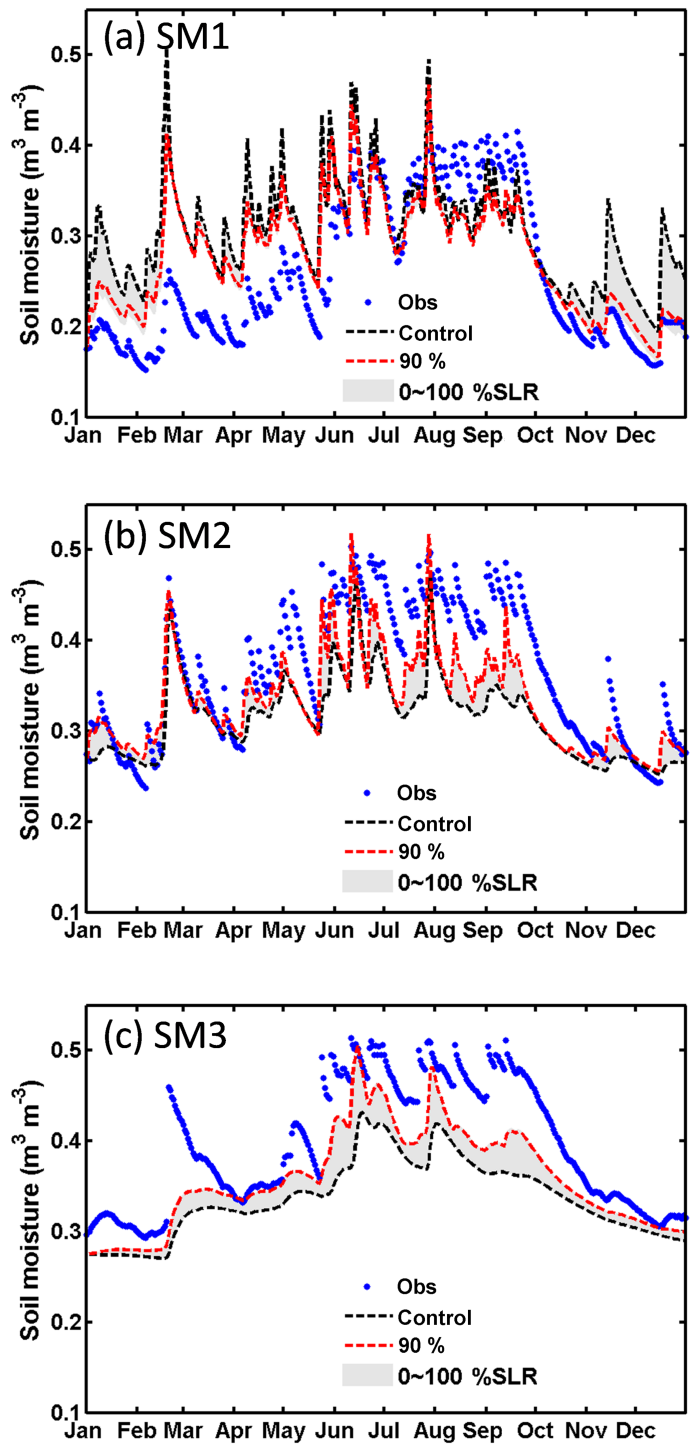

Figure 5. Simulated and observed soil moisture for the LHC site at depths of (a) SM1 $(0-20 \mathrm{~cm})$, (b) SM2 $(20-70 \mathrm{~cm})$ and (c) SM3 $(70-170 \mathrm{~cm})$. Observed results are shown as blue dots. Simulations with SLR $=0$ (i.e., control run, without stem-root flow) and SLR $=90 \%$ are shown as black dashed and red dashed curves, respectively. The area of grey shading enclosed by SLR $=0 \%$ and $100 \%$ indicates the possible range of the stem-root flow effects. All simulation results are daily averages.

mated soil moisture in spring and winter, but underestimated it during autumn. Such discrepancies are generally less substantial when the stem-root flow mechanism is included, as indicated by the generally lower bias and root-mean-square error shown in Table 3. The possible causes of error will be elaborated in the discussion section.

For the HAPEX case, the simulations also captured the seasonal cycle as well as the sharp fluctuations in the top layer well (Fig. 6). The responses of SM2 and SM3 to
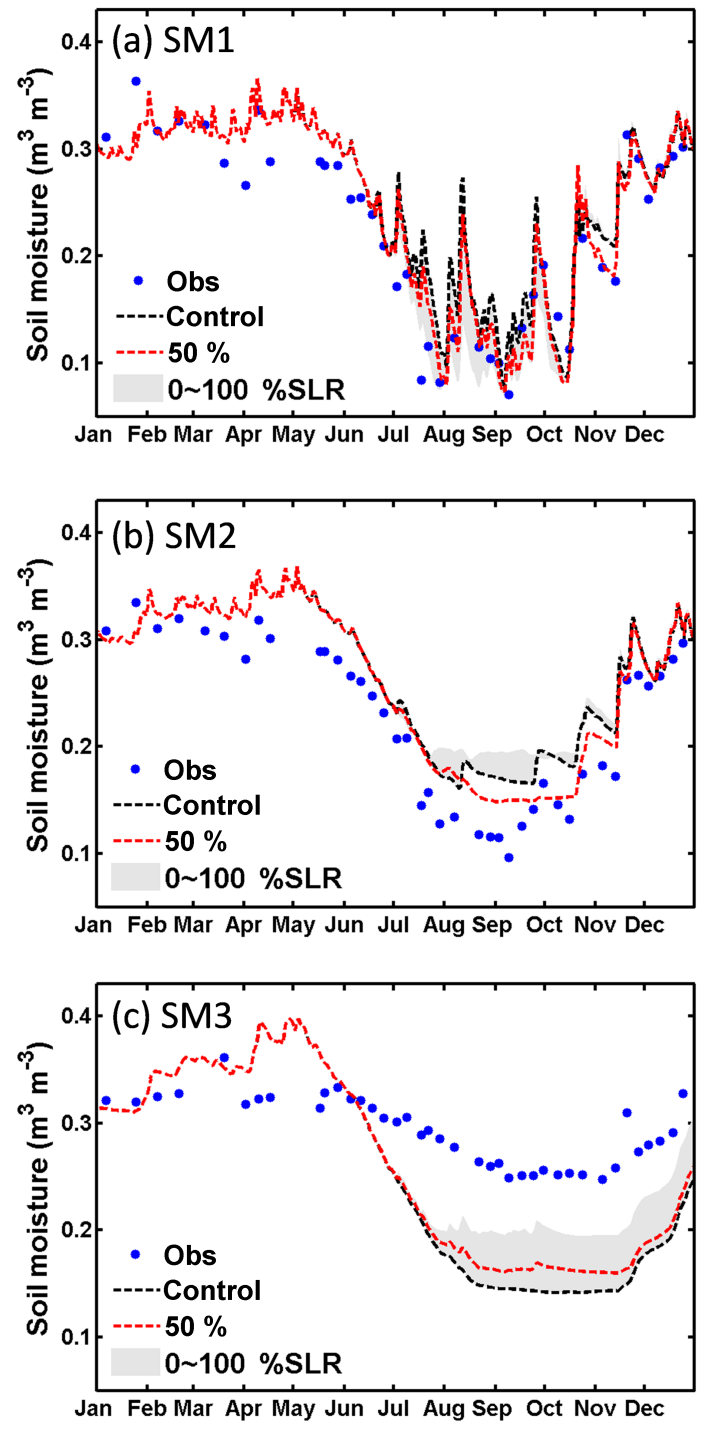

Figure 6. Same as Fig. 5, but for the HAPEX case at depths of (a) SM1 (0-20 cm), (b) SM2 $(20-50 \mathrm{~cm})$ and (c) SM3 $(50-160 \mathrm{~cm})$. Red dashed curves are results with SLR $=50 \%$.

the stem-root flow are statistically significant $(>95 \%$ confidence) during late summer and autumn (the main growing season and relatively dry soil); whereas the responses in SM1 reached only $94 \%$ confidence level. Without the stem-root flow mechanism, soil moisture was generally overestimated in the two upper layers and underestimated in the bottom layer, except during April and May when all layers were too dry. When stem-root flow with SLR $=50 \%$ was considered, the model performed better in all layers (see Table 3). Stemroot flow with a much higher SLR (e.g., SLR $=100 \%$ ) produced worse results for soil moisture in the surface and middle layers. Note that SLR $=50 \%$ produced the driest middle layer, indicating that the stem-root flow effect is nonlinear because both stem-root flow and diffusion, as well as their interactions, play a role in soil moisture variations. Note that 
Table 3. The mean bias, root-mean-square error (RMSE) and standard deviation (SD) in simulated soil moisture compared to observations (obs). Control refers to simulations without the stem-root flow mechanism, and SLR90\% or SLR50\% are simulations with the optimal stemflow to leaf drainage ratio. Unit: $\mathrm{m}^{3} \mathrm{~m}^{-3}$.

\begin{tabular}{lrcc|rcc|ccc}
\hline & \multicolumn{3}{c}{ SM1 } & \multicolumn{3}{c|}{ SM2 } & \multicolumn{3}{c}{ SM3 } \\
\cline { 2 - 9 } & Bias & RMSE & SD & Bias & RMSE & SD & Bias & RMSE & SD \\
\hline LHC control-obs & -0.003 & 0.142 & 0.142 & -0.098 & 0.153 & 0.012 & -0.141 & 0.193 & 0.131 \\
LHC SLR90\%-obs & 0.023 & 0.056 & 0.051 & -0.034 & 0.050 & 0.036 & -0.038 & 0.048 & 0.029 \\
HAPEX control-obs & 0.018 & 0.036 & 0.032 & 0.032 & 0.037 & 0.019 & -0.057 & 0.085 & 0.063 \\
HAPEX SLR50\%-obs & 0.009 & 0.030 & 0.029 & 0.024 & 0.030 & 0.018 & -0.049 & 0.074 & 0.056 \\
\hline
\end{tabular}

Table 4. Mean and maximum changes in daily temperatures and energy fluxes due to the stem-root flow (between optimal SLR run and control run) during the growing season. Canopy air temperature $\left(T_{\mathrm{C}}\right)$, soil surface temperature $\left(T_{\mathrm{S}}\right)$ and leaf temperature $\left(T_{\mathrm{L}}\right)$ are in ${ }^{\circ} \mathrm{C}$; transpiration (TR), soil evaporation (SE), leaf evaporation (LE), sensible heat (SH) and latent heat (LH) are in $\mathrm{W} \mathrm{m}^{-2}$.

\begin{tabular}{lrrrrrrrr}
\hline & $\Delta T_{\mathrm{C}}$ & $\Delta T_{\mathrm{S}}$ & $\Delta T_{\mathrm{L}}$ & $\Delta \mathrm{TR}$ & $\Delta \mathrm{SE}$ & $\Delta \mathrm{LE}$ & $\Delta \mathrm{SH}$ & $\Delta \mathrm{LH}$ \\
\hline LHC mean & 0.32 & 0.31 & 0.34 & 0.20 & -1.19 & 0.31 & 2.02 & -0.68 \\
LHC maximum & 2.90 & 2.59 & 3.18 & 1.01 & -15.50 & 11.34 & 31.44 & -16.81 \\
HAPEX mean & 0.04 & 0.11 & 0.03 & 1.06 & -2.17 & 0.28 & 0.52 & -0.82 \\
HAPEX maximum & 1.27 & 1.63 & 1.70 & -66.74 & -19.5 & 9.95 & 51.16 & -66.29 \\
\hline
\end{tabular}

$\mathrm{SSiB}$ does not consider the potential role of plant uptake, which might be potentially important in the middle layer. In the bottom layer, more accurate soil moisture was obtained with SLR $=100 \%$, but this does not necessarily mean that the stem-root flow was underestimated. The overestimation of soil moisture in SM1 and the underestimation in SM3 in spring may be coupled, due to mechanisms that are missing in our model. This issue will be elaborated in the discussion section.

It is also worth mentioning that both the observation and simulation showed weaker soil moisture fluctuations in the middle than in the surface layer, a feature very different from the LHC case. It is likely that there is a weaker stem-root flow associated with plant and soil types in the HAPEX case. Figures 5 and 6 demonstrate that the strength of the stemroot flow is greater in LHC, with associated changes in soil moisture of up to $0.1 \mathrm{~m}^{3} \mathrm{~m}^{-3}$ compared with the maximum changes of $0.05 \mathrm{~m}^{3} \mathrm{~m}^{-3}$ at HAPEX. This is simply because LHC has more intense rainfall than HAPEX.

\section{Effect of stem-root flow on energy flux}

The results in the last section show that stem-root flow can alter the vertical profile of soil moisture. It is important to know whether such a modification has significant effects on evapotranspiration and associated interactions between the land and atmosphere. The soil moisture in the top soil layer in the LHC case generally decreased due to stem-root flow, except in some instances (e.g., mid-September, the later dry season) when the enhanced moisture storage in the deep layers replenishes the moisture in the drying surface soil through moisture diffusion. The changes in plant transpiration, however, were insignificant (red curve in Fig. 7a), as this process is associated with soil moisture not only in the top layer but also in the deeper layers that are within the reach of the root system. Therefore, the effect of surface layer drying on transpiration may be compensated by the moistening of the lower layers. Soil moisture in these layers is well above the wilting point to support normal transpiration. Meanwhile, the drying of the surface soil resulted in less soil evaporation (Fig. 7a), which heavily relies on soil moisture near the soil surface, and thus weakens the total latent heat release (see Table 4 for the mean and maximum changes in daily temperatures and energy fluxes). This led to a higher soil surface temperature and consequently stronger sensible heat flux (blue curve in Fig. 7b), which resulted in warmer air (magenta curve in Fig. 8b) and thus stronger rainwater evaporation from the leaf surface (green curve in Fig. 7a).

In the HAPEX case, the stem-root flow caused a general drying of the top soil, except for a brief period in midOctober (Fig. 8a). However, responses in soil evaporation were not as straightforward as in the LHC case. For example, in late July (just after the start of the growing season) there was a spike in the evaporation but a reduction in the moisture of the top soil layer (blue curve in Fig. 8a). As wind speed is the same for both cases, the increase in soil evaporation must be due to either a higher soil temperature and/or a lower water vapor density in the air near the soil surface. This was indeed the case (magenta and black curves in Fig. 8b) and found to be driven by changes in transpiration.

Soil moisture in the HAPEX case was generally much lower than in the LHC case and occasionally fell below the 

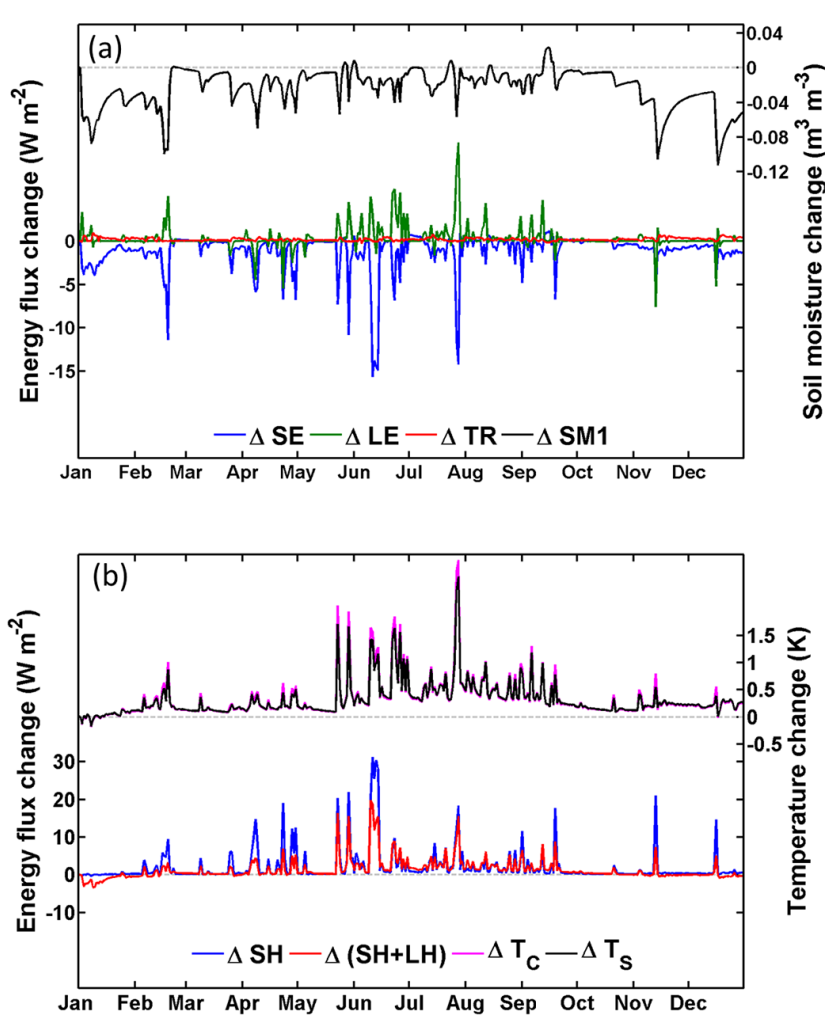

Figure 7. Difference in daily mean heat fluxes and soil moisture due to stem-root flow at the LHC case. (a) Changes in soil evaporation (SE; blue curve), leaf evaporation (LE; green curve), transpiration (TR; red curve) and soil moisture of the surface layer (SM1; black curve; right axis); (b) changes in sensible heat ( $\mathrm{SH}$; blue curve), total heat (sensible heat plus latent heat $(\mathrm{SH}+\mathrm{LH})$; red curve), canopy air temperature $\left(T_{\mathrm{C}}\right.$; magenta curve; right axis) and soil temperature $\left(T_{\mathrm{S}}\right.$; black curve; right axis). Grey dashed lines indicate the zero baseline.

wilting point. The stomatal resistance that controls transpiration is very sensitive to the soil moisture near the wilting point. As such, a slight decrease in the moisture of the top soil layer can dramatically reduce transpiration. When soil moisture approached the wilting point in late July, plant transpiration reduced sharply in response to the stem-root flow effect (red curve in Fig. 8a). Such a change in plant transpiration caused an increase in the air temperature near the soil surface (magenta curve in Fig. 8b) and a decrease in air humidity, which increased soil evaporation (blue curve in Fig 8a). In early August, however, soil moisture accumulated in the bottom layer through the stem-root flow (cf. Fig. 6c) and the stomatal resistance began to decrease such that transpiration recovered and soon dominated the overall evapotranspiration throughout the rest of the growing season. The increased transpiration also caused a reduction in air temperature and surface temperature and thus the associated sensible heat flux (blue curve in Fig. 8b). During late August to mid-September, surface soil moisture was so low in some in-
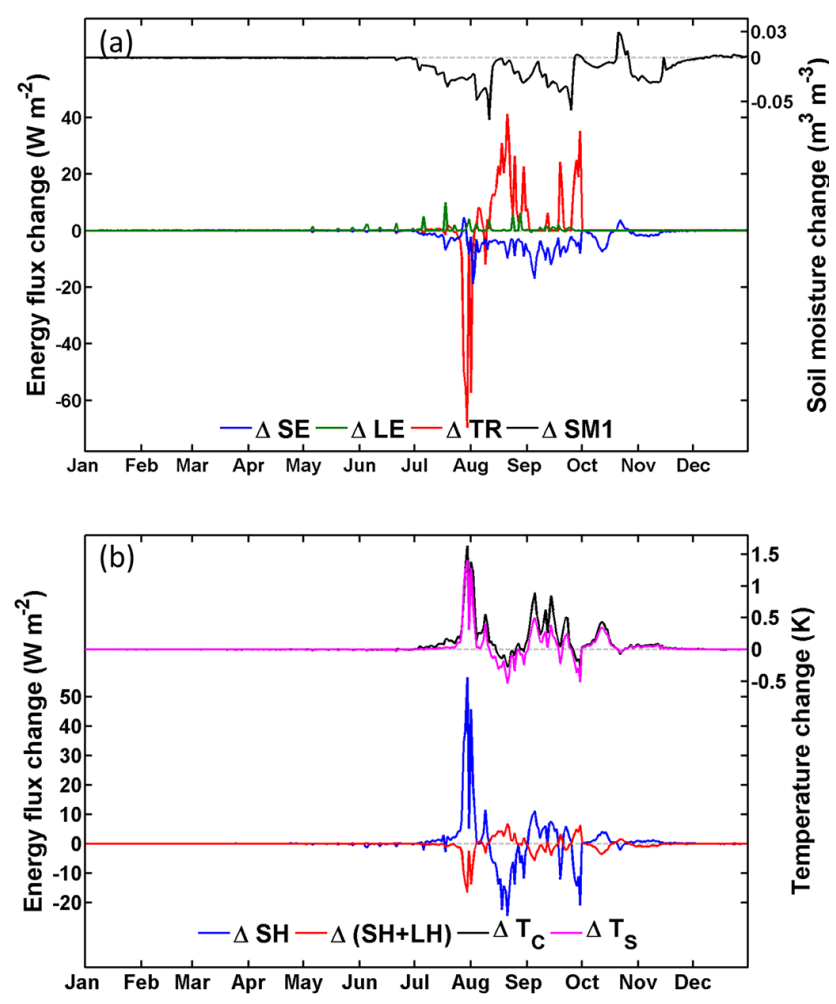

Figure 8. Same as Fig. 7, but for the HAPEX case.

stances (cf. Fig. 6a), that transpiration ceased with or without the stem-root flow effect. In these instances, the net energy flux was controlled by soil evaporation (Fig. 8b).

\section{Discussion}

The above analyses indicate that stem-root flow affects the energy flux mainly through changing the balance between surface soil evaporation and sensible heat fluxes in the humid environment of LHC, and through changing plant transpiration and sensible heat fluxes over the relatively dry environment at HAPEX. The associated changes in annual energy flux to the atmosphere are strongly positive at LHC, but nearly balanced at HAPEX. However, the magnitude of the changes of the individual energy flux component was significantly higher for HAPEX (peaked at approximately -67 and $+51 \mathrm{~W} \mathrm{~m}^{-2}$ for transpiration and sensible heat, respectively) than for LHC (peaked at approximately -16 and $+31 \mathrm{~W} \mathrm{~m}^{-2}$ for evaporation and sensible heat, respectively) due to its drier Mediterranean environment.

Another interesting contrast between the two cases is the relationship between sensible heat and total heat (sensible heat plus latent heat). In the LHC case, the responses of sensible heat and total heat to the stem-root flow are generally of the same sign (Fig. 7b), whereas they have opposite signs in the HAPEX case (Fig. 8b). Furthermore, the net change in heat flux is dominated by sensible heat at LHC 
but by latent heat at HAPEX. Budyko (1974) proposed two main evapotranspiration regimes: soil-moisture-limited and energy-limited. As summarized by Seneviratne et al. (2010), when soil moisture remains above a critical value, the fraction of evapotranspiration of the total energy flux is independent of the soil moisture content (energy-limited regime); below the critical soil moisture value, the soil moisture content provides a first-order constraint on evapotranspiration (soilmoisture-limited regime). Therefore, the evapotranspiration responses to the stem-root flow as discussed above imply that HAPEX is in the soil-moisture-limited regime, whereas LHC is in the energy-limited regime. Note that this regime separation needs to take the contribution of deep soil moisture to transpiration into account.

Regarding the partition of water transport, recent studies (e.g., Jasechko et al., 2013; Good et al., 2015; Wei et al., 2015) have explored the dominant role of transpiration in ecosystem evapotranspiration. The results of this work partially concur with these studies. In other words, the stemroot flow in the plant-soil system could enhance the transpiration, and reduce the soil evaporation, which regulated the partition of evapotranspiration. A number of PILPS studies, including the PILPS-HAPEX experiment (Boone and Wetzel, 1996; Henderson-Sellers, 1995; Shao et al., 1995; Xue et al., 1996), consistently demonstrated that the current land model parameterizations have a weakness in simulating the soil moisture in the dry season. This study, by introducing a parameterization on the stem-root flow mechanism, seeks to help solve this deficiency. With the stem-root flow mechanism, the soil moisture will redistribute in the vertical, leading to better simulated results in each layer, which is important for the evapotranspiration partition.

By including the stem-root flow mechanism, the land surface model appears to better simulate the vertical distribution of soil moisture. However, significant discrepancies still exist in the model based on comparisons with observed data. The discrepancies may be associated with uncertainties in soil-related physical parameters, such as a few that we listed in the earlier sections. For example, a wide range of values have been reported in the literature for the parameter $V_{\mathrm{s}}$. In the above simulations, we assigned $V_{\mathrm{s}}=10^{-4} \mathrm{~m} \mathrm{~s}^{-1}$, which is probably at the low end of the documented values. An additional simulation was performed using a tenfold higher $V_{\mathrm{s}}$ value (i.e., $V_{\mathrm{s}}=10^{-3} \mathrm{~m} \mathrm{~s}^{-1}$ ), and the resulting soil moisture changes were similar to those presented in Figs. 5 and 6, with differences of only a few percent, and thus are barely legible in Figs. 9 and 10. When a smaller value of $V_{\mathrm{s}}=10^{-5} \mathrm{~m} \mathrm{~s}^{-1}$ was used, the effect of stem-root flow on soil moisture was similar but the magnitude of the changes was reduced by approximately $50 \%$. These sensitivity tests give an indication of the uncertainties associated with $V_{\mathrm{s}}$.
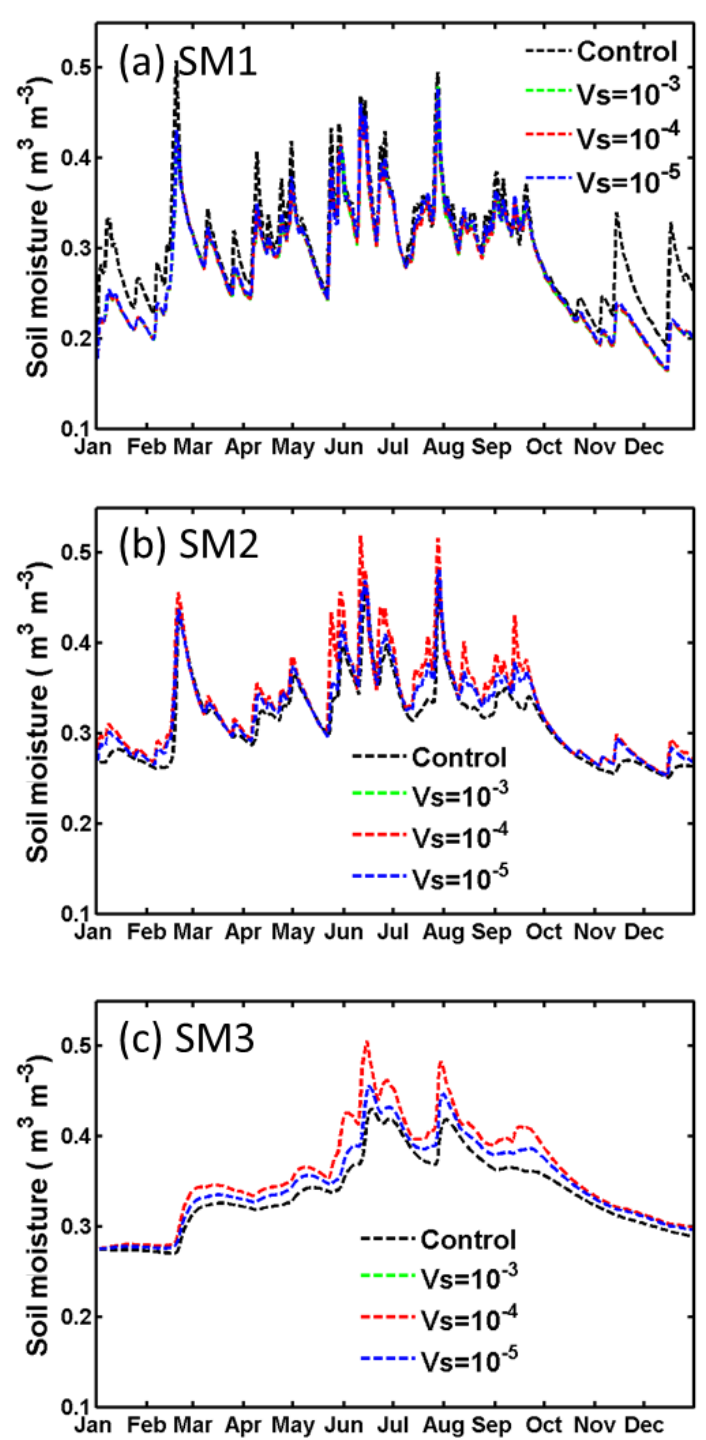

Figure 9. Sensitivity test on $V_{\mathrm{S}}$ for the LHC case with optimal $\mathrm{SLR}=90 \%$ at depths of (a) SM1 $(0-20 \mathrm{~cm})$, (b) SM2 $(20-70 \mathrm{~cm})$ and (c) SM3 $(70-170 \mathrm{~cm})$. The green dashed, red dashed and blue dashed curves are for $V_{\mathrm{s}}=10^{-3}, 10^{-4}$ and $10^{-5} \mathrm{~m} \mathrm{~s}^{-1}$, respectively. Also shown by black dashed curves are the control run results (i.e., $\operatorname{SLR}=0$ ).

Even with the maximum $V_{\mathrm{s}}$, the simulated soil moisture in the bottom layer is still lower than observed. More realistic values for other soil physical parameters and/or optimizations of these parameters are required. Xue et al. (1996) pointed out that land surface models such as $\mathrm{SSiB}$ are quite sensitive to soil-type-dependent parameters such as the hydraulic conductivity at saturation and the coefficient used to calculate soil water potential. Such parameters can vary significantly from place to place, and sufficient information to assign appropriate values is usually lacking. This is particularly true for LHC where the soil types exhibited a rather inhomogeneous vertical distribution, and some humus layers 

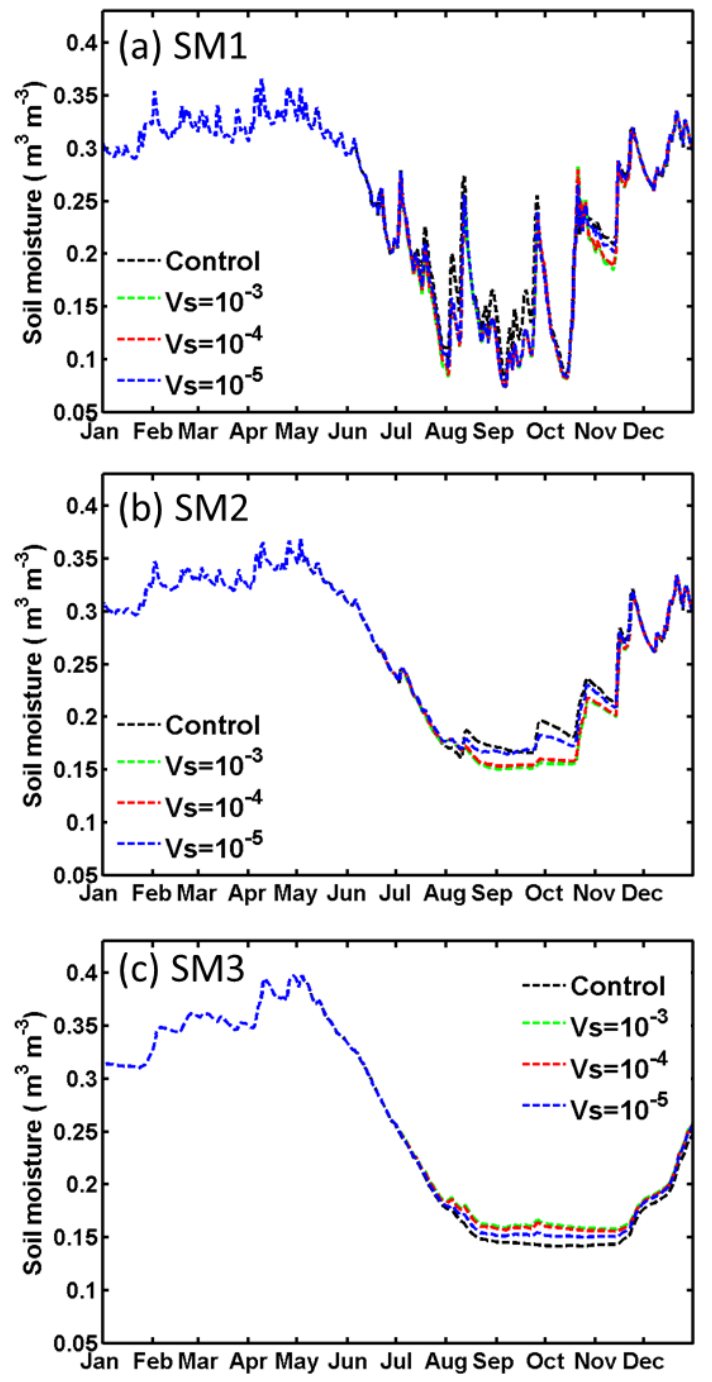

Figure 10. Same as Fig. 9, but SLR $=50 \%$ for the HAPEX case at depths of (a) SM1 $(0-20 \mathrm{~cm})$, (b) SM2 $(20-50 \mathrm{~cm})$ and (c) SM3 $(50-160 \mathrm{~cm})$.

could exist to retard surface drainage. Another critical issue is the treatment of water flow across the bottom soil layer. In our current model, soil moisture can leave the bottom layer with a fixed efficiency, but no recharge from the water table below is allowed. These issues might cause the model to underestimate the soil moisture in the bottom layer (regardless of the presence of stem-root flow), which occurred in both the LHC and HAPEX simulations (cf. Figs. 5c and 6c). On the other hand, the overestimation of soil moisture in SM1 and the underestimation in SM3 in spring at LHC (Fig. 5) could also be explained by missing mechanisms such as hydraulic redistribution (cf. Brooks et al., 2002), which provides a bypass of soil moisture through the inside of the root rather than the exterior surface of the root, as in the case of stem-root flow transport. On the other hand, the overestimation of the middle-layer soil moisture at HAPEX may be partly contributed by the plant uptake process which was not considered in this study. Besides, due to a lack of observational data, we used a uniform vertical distribution of root, which might be the other issue on different effects at the two sites from stem-root flow. In recent years, the U.S. Department of Energy has supported a number of projects to measure the root vertical distribution. With more data becoming available, we should be able to more realistically assess its effects. Henderson-Sellers (1996) indicated that a full evaluation of the land surface model's simulation against observations can be established only when the initial conditions and all soil parameters are known precisely. Because this study lacks process-level data, one should be prudent in the interpretation of model improvements acquired in this study. Since this exploratory study focuses on introducing the stemroot flow mechanism in a land surface model and testing its possible impact, we will not further test the uncertainty due to other parameters in this paper. We hope more relevant measurements (such as the root distribution, stemflow to leaf drainage ratio and root-flow velocity) will provide useful information to study these issues further.

\section{Conclusion}

In this study, a stem-root flow mechanism, which provides an efficient water channel for rain to penetrate into deep soil, was formulated and implemented into an offline version of the SSiB land-atmosphere model. The model was used to simulate soil moisture variation at two sites with different climate and ecology conditions: LHC, with a mountain rainforest climate and HAPEX, with a Mediterranean climate. The results showed that the inclusion of the stem-root flow mechanism substantially improved the capability of the model to simulate vertical soil moisture profiles. Stem-root flow generally caused a drying of the top soil layer (upper $20 \mathrm{~cm}$ ) and a moistening of the bottom layer (below $50 \mathrm{~cm}$ ) in the model. On a few occasions, such as after a long dry period, the surface layer may be less dry than without the stem-root flow due to greater water supply from the lower layers. The middle soil layer at LHC was also moistened and, in many instances during rainfall events, the moisture in this layer fluctuated more intensely than in the top layer in response to the stem-root flow. However, in the HAPEX case, the middle layer became drier with less fluctuation. Due to differences in plant and soil types, the strength of the stem-root flow was greater at LHC than at HAPEX.

The change in soil moisture associated with the stem-root flow leads to significant modifications in heat and moisture fluxes between the land and atmosphere. The general drying of the surface soil leads to reduced soil evaporation and thus increased soil temperature. Plant transpiration at LHC was not significantly affected by the stem flow because the soil moisture content was maintained well above the wilting point. Therefore, the stem-root flow related to energy 
flux between the soil and atmosphere is mainly controlled by sensible heat. In this sense, LHC may be considered as having an energy-limited evapotranspiration regime. In contrast, the HAPEX soil (especially the top layer) was generally drier and sometimes fell below the wilting point. Plant transpiration can thus be substantially affected by the stem-root flow. Changes in transpiration lead to changes in air temperature, which, in turn, influence soil temperature. This effect is stronger than that resulting from the soil evaporation associated with changes in the soil moisture of the top soil layer. At the HAPEX site, evapotranspiration was more soil-moisturelimited than energy-limited, and its net change in heat flux associated with the stem-root flow was dominated by latent heat. While the stem-root flow effect on soil moisture was weaker there than at LHC, the energy flux exchanges were actually stronger due to the sensitive transpiration process.

Through the impact on soil moisture profiles, stemroot flow can significantly affect evaporation and transpiration processes. The associated changes in moisture and energy fluxes between the land and atmosphere may affect boundary-layer stability and convective processes. As evapotranspiration returns as much as $60 \%$ of the precipitation back to the atmosphere over land (Oki and Kanae, 2006), the stem-root flow mechanism may be a key factor in controlling the surface water budget and hydrological cycle. The enhanced storage of water in deep soil layers may have a longterm effect on the climate system. These issues are worthy of further investigation through more relevant observations and testing by coupling the stem-root flow mechanism with global climate models. 
Appendix A: Derivation of $D_{\text {eff }}$

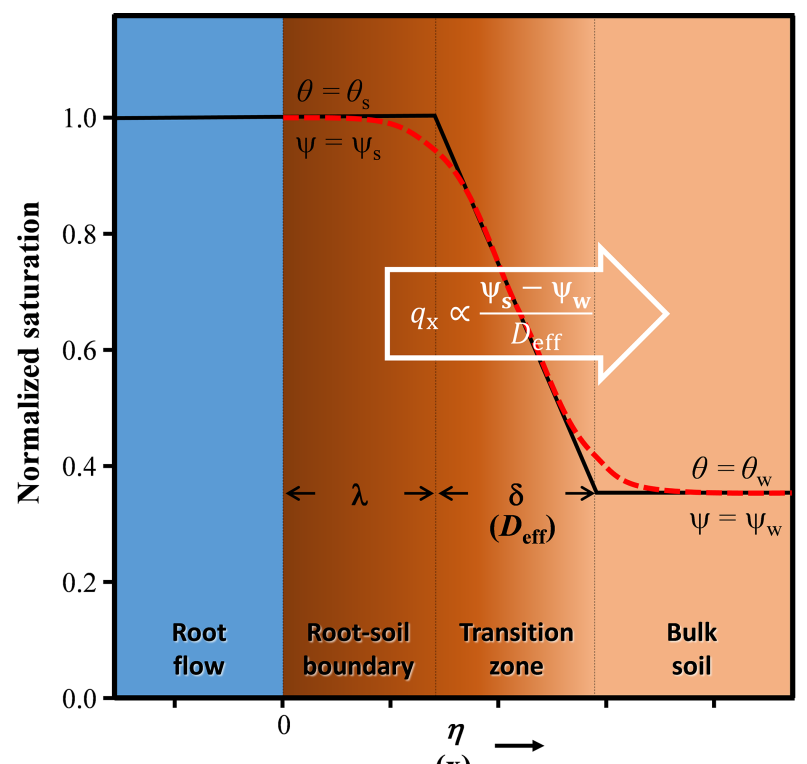

(x)

Figure A1. Schematics of the root flow-soil boundary and soil moisture transition for the parameterization of horizontal water flux $q_{x}$. The red dashed line represents the analytical solution, and the black-solid line represents the parameterization. Soil moisture is saturated (i.e., $\theta_{\mathrm{s}}$ ) in the root-soil boundary (width $\lambda$ ), and decreases linearly in the transition zone (width $\delta$ ) before reaching that of the bulk soil $\left(\theta_{\mathrm{W}}\right)$.

The parameter $D_{\text {eff }}$ in Eq. (4) was derived in a similar fashion as in Zimmerman and Bodvarsson (1991). As shown in Fig. A1, the part of soil next to the root flow absorbs water and form a thin, saturated boundary of width $\lambda$. A gradient of soil moisture is formed in the transition zone (of width $\delta$ ), with soil water potential decrease from the saturated state, $\Psi_{\mathrm{s}}$, to that of the bulk soil, $\Psi_{w}$. Diffusion of soil moisture toward the bulk soil is directly proportional to this gradient.

The soil moisture horizontal ( $x$ direction) movement can be expressed as follows:

$\rho \frac{\partial \theta}{\partial t}=\frac{\partial}{\partial x}\left[K(\Psi) \frac{\partial \Psi}{\partial x}\right]$

where $\rho$ is soil porosity; $\theta$ is the ratio of soil moisture content to its saturated state; $K$ (in m s${ }^{-1}$ ) is the hydraulic conductivity of the soil; $\Psi$ (in $\mathrm{m}$ ) is the soil water potential. Equation (A1) is subject to the following initial and boundary conditions:

$\theta(0, t)=1, \theta(x, 0)=\theta_{\mathrm{w}}, \theta(x \rightarrow \infty, t)=\theta_{\mathrm{w}}$.

The first condition means that when the root flow occurs, soil at the root-soil interface $(x=0)$ is saturated. The next two conditions specify the initial bulk soil moisture content, $\theta_{\mathrm{w}}$, and this value remains unaffected by the root flow at a far distance from the root-soil interface throughout the integration time period.

The hydraulic conductivity and water potential of the soil can be represented with the empirical relationship of Clapp and Hornberger (1978):

$$
\begin{aligned}
& K(\Psi)=K_{\mathrm{S}}\left(\Psi / \Psi_{\mathrm{s}}\right)^{-\frac{3}{b}+2} \\
& \Psi=-\Psi_{\mathrm{s}} \theta^{b},
\end{aligned}
$$

where $K_{\mathrm{S}}\left(\mathrm{in} \mathrm{m} \mathrm{s}^{-1}\right)$ is the hydraulic conductivity at saturation; $b$ is an empirical constant dependent on the soil type. By introducing a similarity variable $\eta$ and two normalized variables $\hat{\Psi}$ and $\hat{K}$,

$\eta \equiv \sqrt{\frac{\rho}{K_{\mathrm{s}} \Psi_{\mathrm{s}} t}}, \hat{\Psi} \equiv \frac{\Psi}{\Psi_{\mathrm{s}}}$ and $\hat{K} \equiv \frac{K}{K_{\mathrm{S}}}$,

Eq. (A1) can be transformed into

$$
\frac{\mathrm{d}}{\mathrm{d} \eta}\left(\hat{K}(\hat{\Psi}) \frac{\mathrm{d} \hat{\Psi}}{\mathrm{d} \eta}\right)+\frac{\eta}{2} \frac{\mathrm{d} \theta}{\mathrm{d} \eta}=0,
$$

whereas the initial and boundary conditions in Eq. (A2) reduced to

$\theta(0)=1, \theta(\eta \rightarrow \infty)=\theta_{w}$.

Zimmerman and Bodvarsson (1991) showed that the solution for Eq. (A6) with conditions in Eq. (A7) can be approximated as

$\begin{cases}\theta=1, & \text { if } 0 \leq \eta \leq \lambda \\ \theta=1-\left(1-\theta_{w}\right) \frac{\eta-\lambda}{\delta}, & \text { if } \lambda<\eta \leq \lambda+\delta, \\ \theta=\theta_{w}, & \text { if } \lambda+\delta<\eta<\infty\end{cases}$

where

$\delta=2 \sqrt{\frac{b}{1+\frac{2}{b\left(1-\theta_{w}\right)}}}$ and $\lambda=\frac{\delta}{b\left(1-\theta_{w}\right)}$.

That is, within the root-soil boundary $(0 \leq \eta \leq \lambda), \theta$ is saturated (i.e., 1); whereas in the transition zone $(\lambda<\eta \leq \lambda+\delta)$, $\theta$ decreases linearly from 1 to $\theta_{w}$. Here, $\delta$ is the effective thickness of diffusion in the $\eta$ coordinate, and it can be reverted back to the $x$ coordinate using the similarity conversion in Eq. (A5):

$D_{\text {eff }}=\delta \sqrt{\frac{K_{\mathrm{s}} \Psi_{\mathrm{s}} t}{\rho}}$.

By applying the actual rainfall duration for $t$ into Eq. (A10), we calculated the mean values of $D_{\text {eff }}=0.005 \mathrm{~m}$ for the HAPEX site and $D_{\text {eff }}=0.03 \mathrm{~m}$ for the LHC site. 
Acknowledgements. This study was supported by the Ministry of Science and Technology of the Republic of China on Taiwan through project MOST-100-2119-M-002-023-MY5. Y. Xue's support is from US NSF AGS-1346813. We are also grateful to S. Sun for technical assistance on SSiB, M.-H. Li and Y.-Y. Chen for providing observation data, W.-L. Liang for helpful suggestions and the National Center for High-performance Computing for computer time and facilities. We also deeply appreciate three reviewers' efforts to provide insightful and constructive comments and suggestions to improve and revise the paper.

Edited by: P. Gentine

\section{References}

André, F., Jonard, M., and Ponette, Q.: Influence of species and rain event characteristics on stemflow volume in a temperate mixed oak-beech stand, Hydrol. Process., 22, 4455-4466, doi:10.1002/hyp.7048, 2008.

Angevine, W. M., Bazile, E., Legain, D., and Pino, D.: Land surface spinup for episodic modeling, Atmos. Chem. Phys., 14, 81658172, doi:10.5194/acp-14-8165-2014, 2014.

Beven, K., and Germann, P.: Macropores and water flow in soils, Water Resour. Res., 18, 1311-1325, 1982.

Böhm, W.: Methods of studying root systems, Springer-Verlag, Berlin, Heidelberg, New York,, 1979.

Boone, A. and Wetzel, P. J.: Issues related to low resolution modeling of soil moisture: experience with the PLACE model, Global Planet. Change, 13, 161-181, 1996.

Brooks, J. R., Meinzer, F. C., Coulombe, R., and Gregg, J.: Hydraulic redistribution of soil water during summer drought in two contrasting Pacific Northwest coniferous forests, Tree Physiol., 22, 1107-1117, 2002

Budyko, M. I.: Climate and Life, Academic Press, New York, 1974.

Chase, T. N., Pielke, R. A., Kittel, T. G. F., Nemani, R., and Running, S. W.: Sensitivity of a general circulation model to global changes in leaf area index, J. Geophys. Res.-Atmos., 101, 73937408, 1996.

Chase, T. N., Pielke Sr., R. A., Kittel, T. G. F., Nemani, R. R., and Running, S. W.: Simulated impacts of historical land cover changes on global climate in northern winter, Clim. Dynam., 16, 93-105, 2000.

Chen, Y.-Y.: Investigating the Seasonal Variability of Surface Heat and Water Vapor Fluxes with Eddy Covariance Techniques: a Subtropical Evergreen Forest as an Example, Doctoral Dissertation, Graduate Institute of Hydrological and Oceanic Sciences, National Central University, Jhongli, 149 pp., 2012.

Clapp, R. B. and Homberger, G. M.: Empirical equations for some soil hydraulic properties, Water Resour. Res., 14, 601-604, 1978.

de Goncalves, L. G. G., Shuttleworth, W. J., Burke, E. J. , Houser, P., Toll, D. L., Rodell, M., and Arsenault, K.: Toward a South America Land Data Assimilation System: Aspects of land surface model spin-up using the Simplified Simple Biosphere, J. Geophys. Res., 111, D17110, doi:10.1029/2005JD006297, 2006.

Dorman, J. L. and Sellers, P. J.: A Global climatology of albedo, roughness length and stomatal resistance for atmospheric general circulation models as represented by the Simple Biosphere Model (SiB), J. Appl. Meteorol., 28, 833-855, 1989.
Gerke, H.: Bypass flow in soil, in: Encyclopedia of Agrophysics, edited by: Gliński, J., Horabik, J., and Lipiec, J., Encyclopedia of Earth Sciences Series, Springer, the Netherlands, 100-105, 2014.

Good, S. P., Noone, D., and Bowen, G.: Hydrologic connectivity constrains partitioning of global terrestrial water fluxes, Science, 349, 175-177, 2015.

Goutorbe, J. P.: A Critical assessment of the Samer network accuracy, in: Land Surface Evaporation, edited by: Schmugge, T. and André, J.-C., Springer, New York, 171-182, 1991.

Goutorbe, J. P. and Tarrieu, C.: HAPEX-MOBILHY data base, in: Land Surface Evaporation, edited by: Schmugge, T. and André, J.-C., Springer, New York, 403-410, 1991.

Goutorbe, J.-P., Noilhan, J., Valancogne, C., and Cuenca, R. H.: Soil moisture variations during HAPEX-MOBILHY, Ann. Geophys., 7, 415-426, 1989.

Henderson-Sellers, A.: Soil moisture simulation: Achievements of the RICE and PILPS intercomparison workshop and future directions, Global Planet. Change, 13, 99-115, 1996.

Henderson-Sellers, A., Pitman, A. J., Love, P. K., Irannejad, P., and Chen, T. H.: The Project for Intercomparison of Land Surface Parameterization Schemes (PILPS): Phases 2 and 3, B. Am. Meteorol. Soc., 76, 489-503, 1995.

Jarvis, N. J. and Dubus, I. G.: State-of-the-art review on preferential flow, www.eu-footprint.org (last access: 5 June 2012), 60 pp., 2006.

Jasechko, S., Sharp, Z. D., Gibson, J. J., Birks, S. J., Yi, Y., and Fawcett, P. J.: Terrestrial water fluxes dominated by transpiration, Nature, 496, 347-350, doi:10.1038/nature11983, 2013.

Johnson, M. S. and Lehmann, J.: Double-funneling of trees: stemflow and root-induced preferential flow, Ecoscience, 13, 324 333, 2006.

Köhne, J. M., Köhne, S., and Šimůnek, J.: A review of model applications for structured soils: a) Water flow and tracer transport, J. Contam. Hydrol. 104, 4-35, 2009.

Levia, D. F. and Frost, E. E.: A review and evaluation of stemflow literature in the hydrological and biochemical cycles of forested and agricultural ecosystems, J. Hydrol., 274, 1-29, 2003.

Levia, D. F. and Germer, S.: A review of stemflow generation dynamics and stemflow-environment interactions in forests and shrublands, Rev. Geophys., 53, 673-714, 2015.

Li, J., He, B., Chen, Y., Huang, R., Tao, J., and Tian, T.: Root distribution features of typical herb plants for slope protection and their effects on soil shear strength, Transactions of the Chinese Society of Agricultural Engineering, 29, 144-152, 2013.

Xiao-Yan Li, Zhi-Peng Yang, Yue-Tan Li, and Henry Lin: Connecting ecohydrology and hydropedology in desert shrubs: stemflow as a source of preferential flow in soils, Hydrol. Earth Syst. Sci., 13, 1133-1144, doi:10.5194/hess-13-1133-2009, 2009.

Li, X.-Y., Lin, H., and Levia, D. F.: Coupling ecohydrology and hydropedology at different spatio-temporal scales in water-limited ecosystems, in: Hydropedology, edited by: Lin, H., Academic Press, Boston, 737-758, 2012.

Liang, W.-L., Kosugi, K., and Mizuyama, T.: Heterogeneous soil water dynamics around a tree growing on a steep hillslope, Vadose Zone J., 6, 879-889, 2007.

Liang, W.-L., Kosugi, K., and Mizuyama, T.: A three-dimensional model of the effect of stemflow on soil water dynamics around a tree on a hillslope, J. Hydrol., 366, 62-75, 2009. 
Lim, Y.-J., Hong, J., and Lee, T.-Y.: Spin-up behavior of soil moisture content over East Asia in a land surface model, Meteorol. Atmos. Phys., 118, 151-161, 2012.

Liu, I.-W. Y., Waldron, L. J., and Wong, S. T. S.: Application of nuclear magnetic resonance imaging to study preferential water flow through root channels, SSSA Spec. Publ., 36, 135-148, 1994.

McGuffie, K., Henderson-Sellers, A., Zhang, H., Durbidge, T. B., and Pitman, A. J.: Global climate sensitivity to tropical deforestation, Global Planet. Change, 10, 97-128, 1995.

Návar, J.: The causes of stemflow variation in three semi-arid growing species of northeastern Mexico, J. Hydrol., 145, 175-190, 1993.

Neave, M. and Abrahams, A. D.: Vegetation influences on water yields from grassland and shrubland ecosystems in the Chihuahuan Desert, Earth Surf. Proc. Land., 27, 1011-1020, 2002.

Oki, T. and Kanae, S.: Global Hydrological Cycles and World Water Resources, Science, 313, 1068-1072, 2006.

Sellers, P. J., Mintz, Y., Sud, Y. C., and Dalcher, A.: A Simple Biosphere Model (SIB) for use within general circulation models, J. Atmos. Sci., 43, 505-531, 1986.

Seneviratne, S. I., Corti, T., Davin, E. L., Hirschi, M., Jaeger, E. B., Lehner, I., Orlowsky, B., and Teuling, A. J.: Investigating soil moisture-climate interactions in a changing climate: A review, Earth-Sci. Rev., 99, 125-161, 2010.

Shao, Y., Anne, R. D., Henderson-Sellers, A., Irannejad, P., Thorton, P., Liang, X., Chen, T. H., Ciret, C., Desborough, C., Barachova, O., Haxeltine, A., and Ducharne, A.: Soil Moisture Simulation, A report of the RICE and PILPS Workshop, GEWEX Tech. Note, IGPO Publ. Ser., 14, 179 pp., 1995.

Siegert, C. M. and Levia, D. F.: Seasonal and meteorological effects on differential stemflow funneling ratios for two deciduous tree species, J. Hydrol., 519, 446-454, 2014.

Tanaka, T., Taniguchi, M., and Tsujimura, M.: Significance of stemflow in groundwater recharge. 2: A cylindrical infiltration model for evaluating the stemflow contribution to groundwater recharge, Hydrol. Process., 10, 81-88, 1996.
Taniguchi, M., Tsujimura, M., and Tanaka, T.: Significance of stemflow in groundwater recharge. 1: Evaluation of the stemflow contribution to recharge using a mass balance approach, Hydrol. Process., 10, 71-80, 1996.

Wei, Z., Yoshimura, K., Okazaki, A., Kim, W., Liu, Z., and Yokoi, M.: Partitioning of evapotranspiration using high-frequency water vapor isotopic measurement over a rice paddy field, Water Resour. Res., 51, 3716-3729, 2015.

Wu, B.-Y.: Simulations of Land Surface Fluxes of the Lien Hua Chih Experimental Watershed with Land Process Models, Master Thesis, Graduate Institute of Hydrological and Oceanic Sciences, National Central University, Jhongli, 100 pp., 2011.

Xue, Y., Sellers, P., Kinter, J., and Shukla, J.: A simplified biosphere model for global climate studies, J. Climate, 4, 345-364, 1991.

Xue, Y., Zeng, F. J., and Schlosser, C. A.: SSiB and its sensitivity to soil properties - a case study using HAPEX-Mobilhy data, Global Planet. Change, 13, 183-194, 1996.

Yang, Y., Uddstrom, M., and Duncan, M.: Effects of short spin-up periods on soil moisture simulation and the causes over New Zealand, J. Geophys. Res., 116, D24108, doi:10.1029/2011JD016121, 2011.

Zhang, Y.-Q., Zhu, Q. K., and Qi, S.: Root system distribution characteristics of plants on the terrace banks and their impact on soil moisture, Acta Ecologica Sinica, 25, 500-506, 2005.

Zhao, M., Pitman, A. J., and Chase, T.: The impact of land cover change on the atmospheric circulation, Clim. Dynam., 17, 467477, 2001.

Zimmerman, R. and Bodvarsson, G.: A simple approximate solution for horizontal infiltration in a Brooks-Corey medium, Transport Porous Med., 6, 195-205, 1991. 